\title{
INVENTÁRIO E RECOMENDAÇÕES PARA A ARBORIZAÇÃO DO CENTRO DA CIDADE DE SÃO JOAQUIM, SC
}

\author{
Patrícia Fukushima de Souza ${ }^{1}$, Cleide Beatriz Bourscheid², Pâmela Niederauer Pompéo², \\ Mariana Bussolo Stang ${ }^{4}$, Jéssica Manfroi ${ }^{5}$, Marcelo Diogo Sousa Rodrigues ${ }^{6}$, \\ Ana Carolina da Silva ${ }^{7}$, Pedro Higuchi ${ }^{8}$
}

\section{RESUMO}

O presente trabalho teve como objetivos realizar o levantamento qualitativo e quantitativo das espécies arbóreas da arborização das praças e das ruas localizadas no centro da cidade de São Joaquim, SC, bem como avaliar e detectar eventuais problemas na arborização, possibilitando fazer recomendações técnicas. Para isso, foi conduzido um censo das árvores presentes nas vias urbanas e nas praças do centro, sendo cada árvore identificada, determinada sua origem, mensurado seu espaço físico disponível e avaliado quanto a sua ocupação no espaço e condições gerais. Foi calculada a densidade relativa de cada espécie (DR) e verificado quais indivíduos necessitam ser substituídos, sendo realizadas sugestões de plantio de espécies nativas da região. Foram encontrados 195 indivíduos pertencentes a 35 espécies. Um total de 158 indivíduos, pertencentes a 25 espécies, eram exóticos, com predominância de Prunus serrulata Lindl. (DR=26,67\%). Em $78 \%$ dos indivíduos foi encontrado ataque de pragas e doenças; em $41 \%$ houve algum tipo de injúria; em $65 \%$ foi constatado poda e $7,18 \%$ apresentaram interferência nos elementos urbanos. Sugere-se o enriquecimento da arborização da cidade com espécies nativas da região, adequadas ao espaço urbano existente e a substituição de indivíduos com injúrias graves, fitossanidade afetada e incompatibilidade da espécie com o espaço disponível.

Palavras-chave: Arborização urbana; Espécies nativas; Prunus serrulata.

Recebido em 15.04.2014 e aceito em 15.05.2015

1 Engenheira Florestal, Universidade do Estado de Santa Catarina (UDESC), Centro de Ciências Agroveterinárias (CAV), Departamento de Engenharia Florestal (DEF), Lages, SC, patyfukushima@hotmail.com.

2 Engenheira Florestal, UDESC, CAV, DEF, Lages, SC, cleidib@gmail.com.

3 Engenheira Florestal, UDESC, CAV, DEF, Lages, SC, pamniederauer@gmail.com.

4 Mestranda em Ciências Florestais, UFPR, DEF, Curitiba, PR, mari_stang@hotmail.com.

5 Graduanda em Engenharia Florestal, UDESC, CAV, DEF, Lages, SC, jessicamanfroi@hotmail.com

6 Engenheiro Florestal, UDESC, CAV, DEF, Lages, SC, marcelo_florestal@hotmail.com.

7 Doutora em Engenharia Florestal, UDESC, CAV, DEF, Lages, SC, carol_sil4@yahoo.com.br.

8 Doutor em Engenharia Florestal, UDESC, CAV, DEF, Lages, SC, higuchip@gmail.com. 


\title{
INVENTORY AND RECOMENDATION FOR THE URBAN FOREST OF SÃO JOAQUIM CITY CENTER, SC
}

\begin{abstract}
This study aimed to conduct a qualitative and quantitative survey of the trees on the streets and squares located at city center of São Joaquim, SC, both to evaluate and detect possible problems of the urban forest, to provide technical recommendations. For this, a census of trees in urban roads and squares at city center was conducted, identifying all trees, determining their origins, measuring their available physical space, evaluating their occupation in the space and general conditions. It was determined the relative density (DR) for each species and it was verified which individuals were required to be replaced, with suggestion of inclusion of regional native species. A total of 195 individuals belonging to 35 species were found. From this total, 158 trees, belonging to 25 species were exotics, with the predominance of Prunus serrulata Lindl. (DR=26.67\%). The attack of pest and diseases, injuries, pruning and interference on urban elements were found in, respectively, in 78, 41, 65 and $7.18 \%$ of the individuals. It is suggested the enhancement of tree species richness with regional native species, adequated to the existent urban space, and the replacement of severe injured individuals, with affected phytosanity and incompatibility in the available space.
\end{abstract}

Keywords: Urban forestry; Native species; Prunus serrulata.

\section{INTRODUÇÃO}

São Joaquim, situada no Planalto Catarinense a aproximadamente $1360 \mathrm{~m}$ de altitude, é considerada uma das cidades mais frias do Brasil, sendo reconhecida pela ocorrência de neve durante o inverno. Por isso, a cidade é procurada por turistas, principalmente durante o inverno, sendo a região central da cidade muito visitada. Suas praças possuem grande importância, pois são pontos turísticos pelas árvores que "congelam" no inverno (devido à aspersão de água), transformando-as em "bosques de gelo" (PREFEITURA MUNICIPAL DE SÃO JOAQUIM, 2014). 
Além da grande importância das praças para a atração de turistas ao município, as áreas verdes urbanas possuem importância ecológica e para a população, pois podem servir para a conservação da flora e da fauna e serem locais de descanso e lazer para a população. No entanto, para a arborização urbana propiciar benefícios à população, ela exige um planejamento criterioso e um manejo adequado. Recomenda-se a utilização de espécies nativas na arborização, pois estas auxiliam na manutenção da fauna nativa, já que diversifica a comunidade de polinizadores, dispersores e herbívoros, proporcionam uma identidade arbórea para a cidade, que serve como atrativo ao turista (SILVA, 2008), e evita a invasão de áreas naturais por espécies exóticas utilizadas na arborização urbana, situação comum no Brasil devido à ampla utilização destas espécies na arborização das cidades.

São poucos os estudos sobre a arborização urbana no Planalto Catarinense, destacando-se os estudos de Pinheiro et al., (2009) em São José do Cerrito e de Reis et al. (2009), Moser et al. (2010), Gross et al. (2012), Küster et al. (2012) e Santos et al. (2013) em Lages, sendo que em São Joaquim não há estudos dessa natureza. Considerando a importância do inventário das árvores nas cidades para o diagnóstico e o planejamento da arborização urbana, os objetivos deste trabalho foram: i) realizar o levantamento qualitativo e quantitativo das espécies arbóreas da arborização das praças e das ruas localizadas no centro da cidade de São Joaquim, SC; ii) avaliar e detectar problemas na arborização atual; e iii) sugerir o enriquecimento da arborização atual com o uso de espécies nativas da região.

\section{MATERIAIS E MÉTODOS}

O estudo foi realizado no centro da cidade de São Joaquim, SC (Figura 1). O município de São Joaquim localiza-se no planalto serrano de Santa Catarina, a $1353 \mathrm{~m}$ de altitude, apresentando clima temperado, com baixas temperaturas no inverno e um verão ameno. A população, segundo o IBGE (2014), é 24812 habitantes. Os solos são de origem basáltica e a vegetação nativa da região é formada por floresta com Araucária que, segundo o IBGE (2012), é classificada como Floresta Ombrófila Mista Alto-Montana. 
Figura 1. Centro da cidade de São Joaquim, no Estado de Santa Catarina

Figure 1. Center of São Joaquim, Santa Catarina State

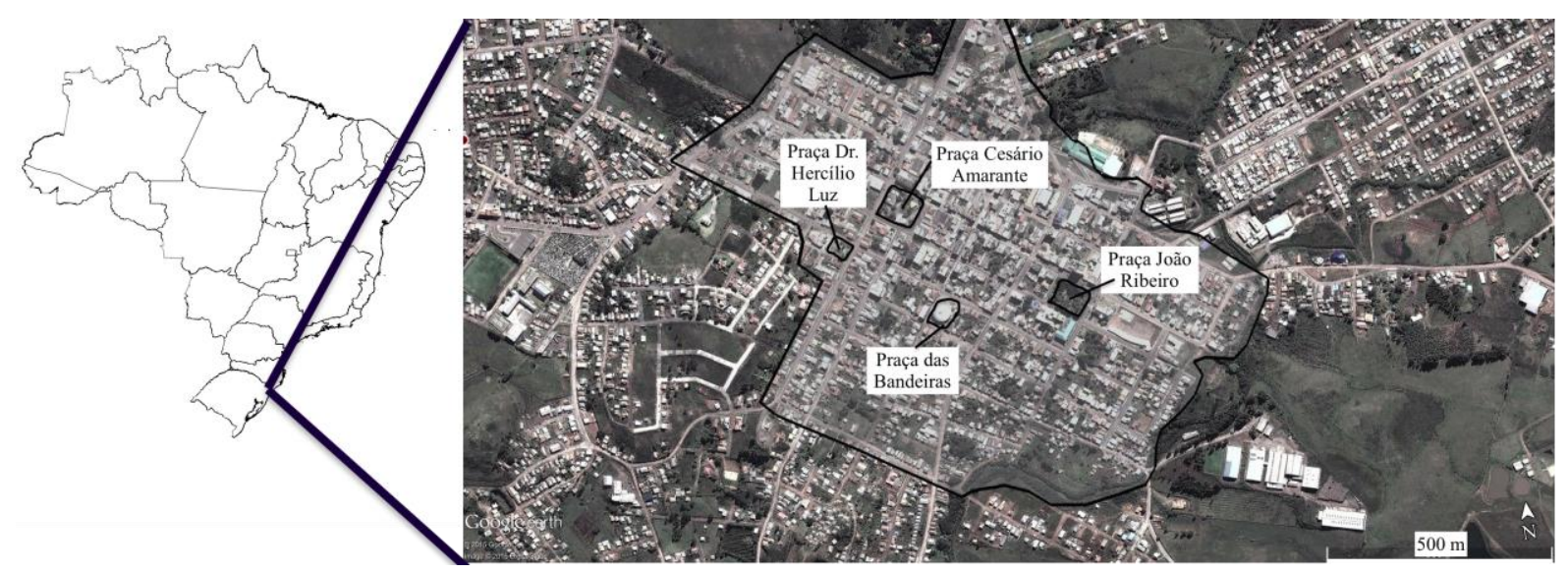

Para o inventário da arborização urbana do centro de São Joaquim, foi realizado o censo das árvores presentes nas vias urbanas e nas praças do centro. Cada árvore foi identificada, determinada sua origem (nativa ou exótica), mensurado seu espaço físico disponível (largura da calçada e largura da rua) e avaliada quanto à sua ocupação no espaço (presença de rede aérea ou outros elementos urbanos) e condições gerais (ataques de pragas e doenças, presença de injúrias e ação e intensidade de podas). Em relação à intensidade das podas, utilizou-se o critério considerado por Volpe-Filik et al. (2007) para poda leve ou pesada, classificando-se os indivíduos em: aqueles que não receberam poda ou aqueles que foram podados, sendo os podados divididos em os que receberam poda leve (galhos podados de até $5 \mathrm{~cm}$ ) ou os que receberam poda pesada (aqueles com galhos podados de diâmetro maior que $5 \mathrm{~cm}$ ).

Os indivíduos de cada espécie foram quantificados, as angiospermas foram classificadas em famílias de acordo com o sistema APG III (ANGIOSPERM PHYLOGENY GROUP, 2009) e as gimnospermas classificadas em famílias de acordo com CHRISTENHUSZ et al. (2011). Foi calculada a densidade relativa de cada espécie (DR, em \%) e foram verificados quais indivíduos necessitam ser removidos ou substituídos.

As sugestões de espécies nativas para a substituição desses indivíduos e para o enriquecimento da arborização das praças e ruas foram feitas com base no estudo fitossociológico de floresta natural de Higuchi et al. (2013). Este estudo foi utilizado como base por ser realizado no município de Painel, SC, limítrofe a São Joaquim, com altitude semelhante. Dessa forma, foram selecionadas espécies amostradas em Painel que apresentavam de pequeno (aquelas que alcançam até $5 \mathrm{~m}$ de altura na fase adulta, segundo o critério de Biondi e Leal, 2009) a médio porte (que alcançam mais que $5 \mathrm{~m}$ e até 
$10 \mathrm{~m}$ de altura, de acordo com critérios dos mesmos autores), mais adequado ao ambiente urbano, e que não apresentavam restrição por ser espécie tóxica ou alergênica. As espécies de grande porte não selecionadas, segundo Biondi e Leal (2009), são aquelas que ultrapassam $10 \mathrm{~m}$ de altura.

\section{RESULTADOS E DISCUSSÃO}

Foram avaliadas quatro praças e 33 ruas presentes no centro de São Joaquim, onde foram encontrados 195 indivíduos arbóreos pertencentes a 35 espécies e a 19 famílias botânicas (Tabela 1). A família com maior riqueza de espécies foi Cupressaceae, com oito espécies, seguido por Rosaceae, com cinco espécies. Um total de 147 indivíduos, pertencentes a 31 espécies, estavam presentes nas praças, e 48 indivíduos, de 10 espécies, estavam nas calçadas das ruas do centro. As praças, devido ao seu maior espaço tridimensional, comportam espécies de diferentes portes e, assim, maior riqueza.

Tabela 1. Espécies arbóreas encontradas no centro de São Joaquim, SC

Table 1. Tree species found at the Center of São Joaquim, SC

\begin{tabular}{|c|c|c|c|c|c|c|}
\hline Famílias & Nomes científicos & Nomes comuns & 0 & $\mathbf{N P}$ & NR & DR \\
\hline Anacardiaceae & $\begin{array}{l}\text { Schinus polygamus (Cav.) } \\
\text { Cabrera }\end{array}$ & Assobiadeira & $\mathrm{N}$ & 1 & 0 & 0,51 \\
\hline Araucariaceae & $\begin{array}{l}\text { Araucaria angustifolia } \\
\text { (Bertol.) Kuntze }\end{array}$ & Araucária & $\mathrm{N}$ & 8 & 2 & 5,13 \\
\hline Arecaceae & $\begin{array}{l}\text { Trachycarpus fortunei } \\
\text { (Hook.) H. Wendl. }\end{array}$ & Palmeira-cabeluda & $E$ & 7 & 0 & 3,59 \\
\hline Asteraceae & $\begin{array}{l}\text { Gochnatia polymorpha } \\
\text { (Less.) Cabrera }\end{array}$ & Cambará & $\mathrm{N}$ & 2 & 0 & 1,03 \\
\hline Bignoniaceae & $\begin{array}{l}\text { Handroanthus albus (Cham.) } \\
\text { Mattos }\end{array}$ & Ipê-da-serra & $\mathrm{N}$ & 0 & 1 & 0,51 \\
\hline \multirow{8}{*}{ Cupressaceae } & $\begin{array}{l}\text { Handroanthus chrysotrichus } \\
\text { (Mart. ex A.DC.) Mattos }\end{array}$ & Ipê-amarelo & $\mathrm{N}$ & 8 & 1 & 4,62 \\
\hline & $\begin{array}{l}\text { Cryptomeria japonica (L. f.) } \\
\text { D. Don }\end{array}$ & Cedro-do-japão & $\mathrm{E}$ & 2 & 0 & 1,03 \\
\hline & $\begin{array}{l}\text { Cunninghamia lanceolata } \\
\text { (Lamb.) Hooker } \mathrm{f} .\end{array}$ & Pinheiro-chinês & $E$ & 1 & 0 & 0,51 \\
\hline & Cupressus funebris Endl. & Ciprest- fúnebre & $E$ & 1 & 0 & 0,51 \\
\hline & \multirow{2}{*}{$\begin{array}{l}\text { Cupressus lusitanica Mill. } \\
\text { Juniperus chinensis } \\
\text { "variegata" L. }\end{array}$} & Cipreste & $E$ & 2 & 0 & 1,03 \\
\hline & & Zimbro & $E$ & 3 & 0 & 1,54 \\
\hline & Thuja occidentalis L. & $\begin{array}{l}\text { Árvore-da-vida- } \\
\text { americana }\end{array}$ & $E$ & 2 & 1 & 1,54 \\
\hline & Thuja orientalis L. & Árvore-da-vida- & $E$ & 2 & 0 & 1,03 \\
\hline
\end{tabular}


Thujopsis dolabrata (Thunb. ex L. f.) Siebold \& Zucc

\begin{tabular}{|c|c|}
\hline $\begin{array}{l}\text { Escalloniaceae } \\
\text { Lithraceae }\end{array}$ & $\begin{array}{l}\text { Escallonia bifida Link. \& Otto } \\
\text { Lagerstroemia indica L. }\end{array}$ \\
\hline Magnoliaceae & $\begin{array}{l}\text { Magnolia } x \text { soulangeana var. } \\
\text { alba-superba }\end{array}$ \\
\hline Meliaceae & Cedrela fissilis Vell. \\
\hline Myrtaceae & $\begin{array}{l}\text { Acca sellowiana (O.Berg) } \\
\text { Burret } \\
\text { Eugenia uniflora L. }\end{array}$ \\
\hline Oleaceae & $\begin{array}{l}\text { Ligustrum lucidum Aiton. } \\
\text { Ligustrum sinense Lour. }\end{array}$ \\
\hline Pinaceae & $\begin{array}{l}\text { Pinus elliotti Engelm. } \\
\text { Pinus taeda L. }\end{array}$ \\
\hline Platanaceae & $\begin{array}{l}\text { Platanus } \mathrm{x} \text { acerifolia (Aiton.) } \\
\text { Willd. }\end{array}$ \\
\hline Podocarpaceae & $\begin{array}{l}\text { Podocarpus lambertii } \\
\text { Klotzsch ex Endl. }\end{array}$ \\
\hline Rosaceae & $\begin{array}{l}\text { Cotoneaster franchetii Bois. } \\
\text { Malus sp. } \\
\text { Prunus persica (L.) Batsch } \\
\text { Prunus serrulata Lindl. } \\
\text { Pyracantha coccinea M. } \\
\text { Roem. }\end{array}$ \\
\hline Salicaceae & Populus alba L. \\
\hline Sapindaceae & $\begin{array}{l}\text { Acer negundo } \mathrm{L} \text {. } \\
\text { Acer palmatum Thunb. }\end{array}$ \\
\hline Theaceae & Camellia japonica L. \\
\hline
\end{tabular}

chinesa

Árvore-da-vida-de-hiba $\quad$ E $\quad 1 \quad 0 \quad 0,51$

Canudo-de-pito

Extremosa

Magnólia

Cedro-rosa

Goiabeira-serrana

Pitangueira

Alfeneiro, ligustro

Ligustrinho

Pinus

Pinus

Plátano, cicônoro

Pinheiro-bravo

Cotoneaster

Macieira

Pessegueiro

Cerejeira-do-japão

Espinho-de-fogo

Álamo-branco

Bôrdo-negundo

Acer

Camélia

$\begin{array}{cccc}\mathrm{N} & 1 & 0 & 0,51 \\ \mathrm{E} & 0 & 4 & 2,05 \\ \mathrm{E} & 2 & 0 & 1,03 \\ \mathrm{~N} & 2 & 1 & 1,54 \\ \mathrm{~N} & 8 & 0 & 4,10 \\ \mathrm{~N} & 1 & 0 & 0,51 \\ \mathrm{E} & 8 & 27 & 17,95 \\ \mathrm{E} & 1 & 0 & 0,51 \\ \mathrm{E} & 1 & 0 & 0,51 \\ \mathrm{E} & 2 & 0 & 1,03 \\ \mathrm{E} & 26 & 0 & 13,33\end{array}$

$\begin{array}{llll}N & 1 & 0 & 0,51\end{array}$

E 1100,51

E $\quad \begin{array}{lll}0 & 2 & 1,03\end{array}$

$\begin{array}{llll}\text { E } & 44 & 8 & 26,67\end{array}$

$\begin{array}{llll}\text { E } & 1 & 0 & 0,51\end{array}$

$\begin{array}{llll}\text { E } & 3 & 0 & 1,54\end{array}$

E $3 \quad 0 \quad 1,54$

E $\quad 0 \quad 1 \quad 0,51$

$147 \quad 48 \quad 100,00$

E $\quad 1 \quad 0 \quad 0,51$

E $\quad 1 \quad 0 \quad 0,51$

$\mathrm{O}=$ origem, sendo $\mathrm{E}$ exótica e $\mathrm{N}$ nativa; $\mathrm{NP}$ = número de indivíduos encontrados nas praças; $\mathrm{NR}=$ número de indivíduos encontrados nas calçadas das ruas; $\mathrm{DR}=$ densidade relativa, em \%

Todas as praças e ruas avaliadas apresentavam arborização. As ruas com menos de $14 \mathrm{~m}$ de largura, incluindo os passeios de ambos os lados, sem afastamento da construção civil em relação ao limite da rua (recuo), representaram apenas $23 \%$ do total analisado. Ruas com estas configurações, segundo CESP (1988), não devem apresentar arborização ou devem receber somente plantas pequenas ou arvoretas (árvores de menos de $5 \mathrm{~m}$ de altura). Destaca-se que, apesar de CESP (1988) tratar especificamente da arborização para o Estado de São Paulo, este trabalho representa uma importante referência para outros estados do país.

As ruas com mais de $14 \mathrm{~m}$ de largura, com recuo uniforme, foram mais representativas (77\%). Esses locais podem ser adornados com árvores de porte médio (até $10 \mathrm{~m}$ de altura), do lado apropriado para sombreamento dos pedestres, veículos e 
residências (CESP, 1988). Para a arborização de ruas, especialmente onde há fiação elétrica, deve ser priorizada espécies de pequeno porte (até $5 \mathrm{~m}$ de altura). De acordo com Soares (1998), árvores de grande porte (aquelas acima de $10 \mathrm{~m}$ de altura) não são indicadas para arborização de calçadas, já que impedem a insolação de fachadas, os galhos podem projetar-se em direção aos prédios, causando desconforto aos moradores, as folhagens podem ser jogadas pelo vento para as calhas, além do sistema radicular de algumas espécies poderem levantar as calçadas, prejudicando, assim, os encanamentos ou fiações subterrâneas. No entanto, foram encontrados cinco indivíduos arbóreos pertencentes a quatro espécies de grande porte nas calçadas: Araucaria angustifolia (Bertol.) Kuntze, Handroanthus albus (Cham.) Mattos, Cedrela fissilis Vell. e Thuja occidentalis L. Em cidades com ventos intensos, algumas espécies podem, ainda, serem susceptíveis ao tombamento e causar acidentes, como observado por Moser et al. (2010) em Lages, SC, para Araucaria angustifolia. Nesses casos, espécies de maior porte podem maximizar a ocorrência de acidentes a pedestres e mobiliários urbanos.

Dos 195 indivíduos identificados, 158 pertenceram a espécies exóticas (25 espécies) e apenas 37 a espécies nativas (10 espécies). A espécie nativa que obteve maior número de indivíduos foi a Araucaria angustifolia (10), seguida pelo Handroanthus chrysotrichus (Mart. ex A.DC.) Mattos (nove) e Acca sellowiana (O.Berg) Burret (oito) (Tabela 1). Mesmo sendo as espécies nativas com maior número de indivíduos, a somatória dos indivíduos dessas três espécies foi inferior ao número de indivíduos da espécie exótica de maior representatividade (Prunus serrulata Lindl., com 52 indivíduos).

O grande número de espécies e de indivíduos exóticos encontrados reflete a realidade de muitas cidades brasileira (e.g. Pato Branco, PR, estudo de Silva et al., 2008, Nova Iguaçu, RJ, estudo de Rocha et al., 2004), onde é comum a utilização de espécies exóticas na arborização urbana. Um dos fatores que explicam o uso limitado de espécies nativas na arborização urbana é a falta de informação sobre essas espécies e o seu comportamento no meio urbano (BIONDI; ALTHAUS, 2005). A diversidade étnica pode explicar em parte a presença de algumas espécies exóticas amplamente empregadas na arborização de São Joaquim. Um exemplo disso é presença expressiva de Prunus serrulata, espécie culturalmente apreciada pelos japoneses, frequentes no município. Neste sentido, apesar da sugestão do enriquecimento com espécies nativas da região de São Joaquim, a manutenção de algumas espécies exóticas, como o Prunus serrulata, por exemplo, é importante para os moradores da cidade.

É possível visualizar a grande participação da família Rosaceae (Figura 2), representada por cinco espécies na área, todas exóticas, destacando-se o grande número 
de indivíduos de Prunus serrulata e a utilização na arborização de espécies da fruticultura da região, como Malus sp. (macieira) e Prunus persica (L.) Batsch (pessegueiro). Rosaceae alcançou o valor recomendado por Santamour Junior (1990) de porcentagem máxima de ocorrência de indivíduos de uma família, que é de $30 \%$ da arborização total. Além disso, Prunus serrulata (DR=26,67\%), assim como Ligustrum lucidum Aiton. (DR=17,95\%) e Platanus x acerifolia (Aiton.) Willd. (DR=13,33\%), ultrapassaram a recomendação de densidade relativa para a espécie, que é de 10\%, e, no caso do Prunus serrulata, também do gênero, que é de $20 \%$. Santamour Junior (1990) recomenda estas porcentagens como o limite máximo para garantir maior diversidade de espécies arbóreas na paisagem urbana a fim de se ter maior proteção contra pragas e doenças. Além disso, a maior diversidade de árvores pode aumentar a diversidade funcional (CADOTTE et al., 2011), elevando o fornecimento de hábitat e alimento para a fauna, permitindo maior variedade nas relações ecológicas.

Figura 2. Porcentagem de indivíduos por família botânica catalogada no centro de São Joaquim, SC

Figure 2. Percentage of individuals per botanical families recorded at city Center of São Joaquim, SC

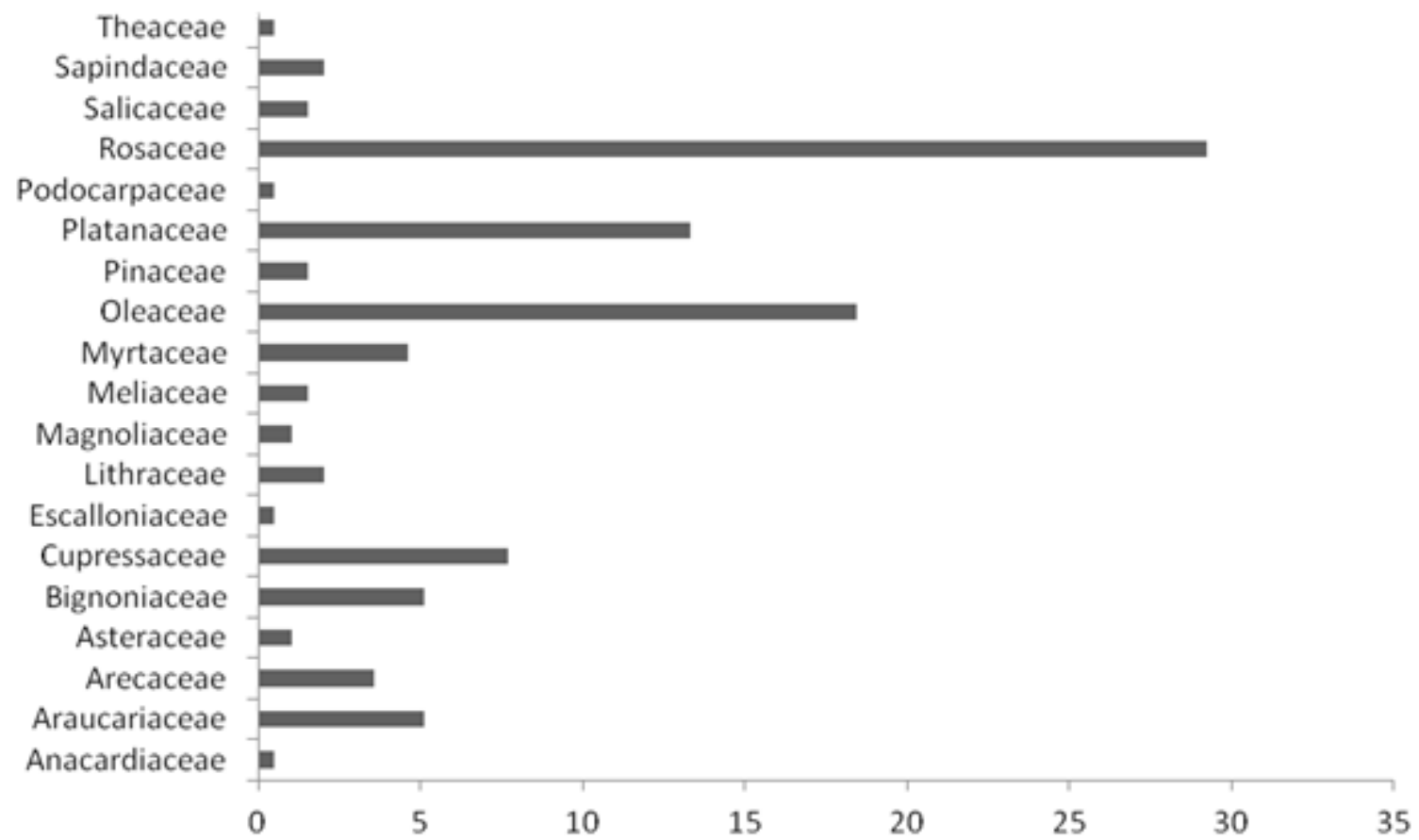

A elevada densidade de poucas espécies, associada à suscetibilidade dessas aos fitopatógenos, pode estar refletindo na elevada porcentagem de ataques de pragas e 
doenças, observadas em 78\% dos indivíduos. Segundo Silva Filho e Bortoleto (2005), a baixa diversidade de espécies nas cidades pode favorecer a propagação de pragas e doenças, sendo recomendável, portanto, o enriquecimento da arborização, especialmente com espécies nativas da região.

Injúrias e vandalismo também são ocorrências comuns em centros urbanos, sendo que $41 \%$ dos indivíduos do presente estudo apresentavam algum tipo de injúria, especialmente no tronco da árvore, por vandalismo. Em Pato Branco, PR, Emer et al. (2013) verificaram injúria em $20 \%$ das árvores, decorrentes, principalmente, de podas drásticas por técnicas inadequadas de corte de galhos, que "lascavam" o tronco, e por vandalismo. Assim, é recomendável a implantação de programas de educação ambiental, a fim de valorizar as árvores urbanas.

A poda foi observada na maioria das árvores (65\%). Destas, $14 \%$ receberam poda pesada e $86 \%$ poda leve, sendo que a poda pesada esteve relacionada à poda de rebaixamento, devido à rede aérea de luz e de telefone em contato com as copas. Esse tipo de problema ocorre devido ao plantio de espécies de portes inadequados ao espaço urbano disponível, sendo recomendável, portanto, a substituição por espécies de menor porte, a fim de evitar podas drásticas (BOBROWSKI; BIONDI, 2012; SANTOS et al., 2013).

De acordo com Pivetta e Silva Filho (2002), a poda é uma prática antiga, utilizada em jardins clássicos europeus e em espécies frutíferas, visando uniformizar a produção de frutas. Devido a essa cultura, no meio urbano ainda há a poda com fins estéticos, por crenças errôneas de que esta irá revigorar a árvore, ou por necessidade de manutenção. Mas tal procedimento pode se tornar necessário para evitar problemas com as redes de transporte de energia, fins estéticos, interposição de copas ou mesmo injúrias graves onde há necessidade de retirada de partes da planta.

É sugerido o enriquecimento da arborização da cidade com espécies nativas da região, adequadas ao espaço urbano existente (Tabela 2), e a substituição de indivíduos com injúrias graves, fitossanidade visivelmente afetada e incompatibilidade da espécie com o espaço disponível, além de sua não recomendação para a arborização por causarem alergias ou invasões de florestas naturais. A Praça Dr. Hercílio Luz, por exemplo, apresentou um indivíduo de Prunus serrulata com injúria grave, que deve ser substituído por um indivíduo de pequeno porte. Já em relação à interferência nos elementos urbanos, do total de árvores inventariadas, 7,18\% interferiram na rede aérea, sendo cinco indivíduos de Platanus acerifolia na Praça João Ribeiro, sete indivíduos de Prunus serrulata e um de Escallonia bifida Link. \& Otto na Praça Cesário Amarante e um indivíduo de Prunus persica nas ruas. 
Tabela 2. Espécies indicadas para o enriquecimento e substituição de alguns indivíduos na arborização do centro de São Joaquim, SC

Table 2. Species indicated for richness enhancement and for replacement of some individuals in the urban forest at city Center of São Joaquim, SC

\begin{tabular}{llc}
\hline \multicolumn{1}{c}{ Famílias } & \multicolumn{1}{c}{ Espécies } & Porte \\
\hline Aquifoliaceae & llex taubertiana Loes. & $\mathrm{M}$ \\
\hline Celastraceae & Maytenus muelleri Schwacke & $\mathrm{P}$ \\
\hline Dicksoniaceae & Dicksonia sellowiana Hook. & $\mathrm{M}$ \\
\hline Fabaceae & Inga lentiscifolia Benth & $\mathrm{M}$ \\
\hline & Acca sellowiana (O.Berg) Burret & $\mathrm{P}$ \\
& Calyptranthes concinna DC. & $\mathrm{M}$ \\
& Myrceugenia euosma (O.Berg) D.Legrand & $\mathrm{M}$ \\
Myrtaceae & Myrceugenia myrcioides (Cambess.) O.Berg & $\mathrm{M}$ \\
& Myrceugenia ovata (Hook. \& Arn.) O.Berg & $\mathrm{M}$ \\
& Myrceugenia oxysepala (Burret) D.Legrand \& Kausel & $\mathrm{P}$ \\
\hline Sapindaceae & Myrrhinium atropurpureum Schott & $\mathrm{M}$ \\
\hline Winteraceae & Drimys angustifolia Miers & $\mathrm{M}$ \\
\hline pequeno porte, até 5 & $\mathrm{m}$ de altura; M = médio porte, mais que 5 m e até 10 m de altura
\end{tabular}

Ligustrum lucidum é amplamente cultivado na arborização no Brasil, especialmente na região Sul do país, onde é encontrado de forma abundante (e.g. SILVA et al., 2007; BIONDI; PEDROSA-MACEDO, 2008; SILVA et al., 2008; PINHEIRO et al., 2009; REIS et al., 2009; LIMA NETO et al., 2010; MELO; SEVERO, 2010; REDIN et al., 2010; SCHALLENBERGER et al., 2010; TOSCAN et al., 2010; BIONDI; MULLER, 2013), podendo se tornar invasor de fragmentos florestais naturais, como já observado por Reginato et al. (2008) e Guidini (2013). Além disso, espécies de Ligustrum podem ser prejudiciais à saúde devido ao pólen alergênico (CARIÑANOS et al., 2002). Dessa forma, é recomendável suas substituições tanto nas praças como nas calçadas das ruas.

\section{CONCLUSÕES}

A arborização urbana do centro da cidade de São Joaquim caracteriza-se por apresentar um padrão típico das demais cidades do Sul do Brasil, representado pelo predomínio de espécies exóticas, com destaque para Prunus serrulata. Apesar da baixa 
interferência nos elementos urbanos, 7,18\% das árvores inventariadas, foi observado um grande percentual de árvores atacadas por pragas e doenças, com algum tipo de injúria e com podas. Recomenda-se a substituição dos indivíduos que estejam interferindo nos elementos urbanos ou que apresentavam injúrias ou ataques por pragas ou doenças. Para este propósito e, também, para aumentar a riqueza de espécies da arborização urbana, recomenda-se o uso de espécies nativas regionais.

\section{REFERÊNCIAS}

ANGIOSPERM PHYLOGENY GROUP. An update of the Angiosperm Phylogeny Group classification for the orders and families of flowering plants: APG III. Botanical Journal of the Linnean Society, Hoboken, v. 161, n. 2, p. 105-121, 2009.

BIONDI, D.; ALTHAUS, M. Árvores de rua de Curitiba: cultivo e manejo. Curitiba: FUPEF, 2005.

BIONDI, D.; PEDROSA-MACEDO, J. H. Plantas invasoras encontradas na área urbana de Curitiba (PR). Floresta, Curitiba, v. 38, n. 1, p. 129-144, 2008.

BIONDI, D. LEAL, L. Avaliação de espécies plantadas experimentalmente na arborização de ruas da cidade de Curitiba - PR. Revista da Sociedade Brasileira de Arborização Urbana, Piracicaba, v. 4, n. 4, p. 79-99, 2009.

BIONDI, D.; MULLER, E. Espécies arbóreas invasoras no paisagismo dos parques urbanos de Curitiba, PR. Floresta, Curitiba, v. 43, n. 1, p. 69-82, 2013.

BOBROWSKI, R.; BIONDI, D. Caracterização do padrão de plantio adotado na arborização de ruas de Curitiba, Paraná. Revista da Sociedade Brasileira de Arborização Urbana, Piracicaba, v. 7, n. 3, p. 20-30, 2012.

CADOTTE, M. W.; CARSCADDEN, K.; MIROTCHNICK, N. Beyond species: functional diversity and the maintenance of ecological processes and services. Journal of Applied Ecology, Londres, v. 48, n. 5, p. 1079-1087, 2011.

CARIÑANOS, P.; ALCÁZAR, P.; GALÁN, C.; DOMÍNGUEZ, E. Privet pollen (Ligustrum sp.) as potential cause of pollinosis in the city of Cordoba, south-west Spain. Allergy, Hoboken, v. 57, n. 2, p. 92-97, 2002. 
CESP - CONPANHIA DE ENERGIA ELÉTRICA DA SÃO PAULO. Guia de arborização. 3. Ed. São Paulo: Coleção Ecossistemas Terrestres, 1988.

CHRISTENHUSZ, M.J.M.; REVEAL, J.L.; FARJON, A.; GARDNER, M.F.; MILL, R.R.; CHASE, M.W. A new classification and linear sequence of extant gymnosperms. Phytotaxa, Auckland, v. 19, n. 1, p. 55-70, 2011.

EMER, A. A.; SILVA, L.; CADORIN, D. A.; MELLO, N. A. Avaliação quantitativa e qualitativa da arborização do bairro Santa Terezinha na cidade de Parto Branco (PR). Ambiência, Guarapuava, v. 9, n. 1, p. 129-143, 2013.

GROSS, A.; DORS, P.; CAMPOS, K. A.; SILVA, A. C.; HIGUCHI, P. Percepção dos moradores e avaliação da arborização em bairros periféricos na cidade de Lages, SC. Revista da Sociedade Brasileira de Arborização Urbana, Piracicaba, v. 7, n. 2, p. 24-36, 2012.

GUIDINI, A. L. Contaminação biológica por espécies arbóreas invasoras em remanescentes florestais no Planalto Sul Catarinense. Lages, 2013. 40f. Dissertação (Mestrado em Engenharia Florestal) - Universidade do Estado de Santa Catarina, Lages, 2013.

HIGUCHI, P.; SILVA, A. C.; ALMEIDA, J. A.; BORTOLUZZI, R. L. C.; MANTOVANI, A.; FERREIRA, T. S.; SOUZA, S. T.; GOMES, J. P.; SILVA, K. M. Florística e estrutura do componente arbóreo e análise ambiental de um fragmento de Floresta Ombrófila Mista AltoMontana no município de Painel, SC. Ciência Florestal, Santa Maria, v. 23, n. 1, p. 153164, 2013.

IBGE. Manual técnico da vegetação brasileira. Rio de Janeiro: Fundação Instituto Brasileiro de Geografia e Estatística, 2012.

IBGE. Censo demográfico de 2010. Disponível em <http://www.censo2010.ibge.gov.br/ sinopse/index.php?uf=42\&dados=8>. Acesso em: 29 jul. 2014.

KÜSTER, L. C.; STEDILLE, L. I. B.; DACOREGIO, H.; SILVA, A. C.; HIGUCHI, P. Avaliação de riscos e procedência de espécies arbóreas nas escolas estaduais de Lages, SC. Revista de Ciências Agroveterinárias, Lages, v. 11, n. 2, p. 118-125, 2012.

LIMA NETO, E. M.; BARDELLI-DA-SILVA, M. Y.; SILVA, A. R.; BIONDI, D. Arborização de ruas e acessibilidade no Bairro Centro de Curitiba-PR. Revista da Sociedade Brasileira de Arborização Urbana, Piracicaba, v. 5, n. 4, p. 40-56, 2010.

MELO, E. F. R. Q.; SEVERO, B. M. A. Avenida Brasil (Passo Fundo, Rio Grande do Sul): diversidade da vegetação e qualidade ambiental. Revista da Sociedade Brasileira de Arborização Urbana, Piracicaba, v. 5, n. 3, p. 01-17, 2010. 
MOSER, P.; SILVA, A. C.; HIGUCHI, P.; SANTOS, E. M.; SCHMITZ, V. Avaliação póstempestade da arborização do campus da Universidade do Estado de Santa Catarina em Lages, SC. Revista da Sociedade Brasileira de Arborização Urbana, Piracicaba, v. 5, n. 2, p. 36-46. 2010.

PINHEIRO, R.; FRANCHIN, E.; RIBEIRO, R. S.; WOLFF, W.; SILVA, A. C.; HIGUCHI, P. Arborização urbana na cidade de São José do Cerrito, SC: diagnóstico e proposta para áreas de maior trânsito. Revista da Sociedade Brasileira de Arborização Urbana, Piracicaba, v. 4, n. 4, p. 63-78, 2009.

PIVETTA, K. F. L.; SILVA FILHO, D. F. Arborização Urbana. Boletim Acadêmico - Série Arborização Urbana. Jaboticabal: UNESP/FCAV/FUNEP. 2002.

PREFEITURA MUNICIPAL DE SÃO JOAQUIM. Disponível em: <http://www.sao joaquim.sc.gov.br>. Acesso em: 15 mar. 2014.

REGINATO, M.; MATOS, F. B.; LINDOSO, G. S.; SOUZA, C. M. F.; PREVEDELLO, J. A.; MORAIS, J. W.; EVANGELISTA, P. H. L. A vegetação na Reserva Mata Viva, Curitiba, Paraná, Brasil. Acta Biológica Paranaense, Curitiba, v. 37, n. 3-4, p. 229-252, 2008.

REDIN, C. G.; VOGEL, C.; TROJAHN, C. D. P.; GRACIOLI, C. R.; LONGHI, S. J. Análise da Arborização Urbana em Cinco Praças do Município de Cachoeira do Sul, RS. Revista da Sociedade Brasileira de Arborização Urbana, Piracicaba, v. 5, n. 3, p. 149-164, 2010.

REIS, C. A. M.; SILVA, A. C.; HIGUCHI, P.; SOUZA, S. T.; FERREIRA, C. J. S. M.; MICHELON, B.; MORO, L. Diagnóstico da vegetação arbórea e proposta de arborização do Rio Carahá na cidade de Lages, SC. Revista da Sociedade Brasileira de Arborização Urbana, Piracicaba, v. 4, n. 3, p. 130-142, 2009.

ROCHA, R. T.; LELES, P. S. S.; OLIVEIRA NETO, S. N. Arborização de vias públicas em Nova Iguaçu, RJ: o caso dos bairros Rancho Novo e Centro. Revista Árvore, Viçosa, v. 28, n. 4, p. 599-607, 2004.

SANTAMOUR JUNIOR, F.S. Trees for urban planting: diversity, uniformity, and common sense. In: METRIA CONFERENCE, 7., 1990, Lisle. Proceedings... Lisle, 1990. p. 57-66.

SANTOS, E. M.; SILVEIRA, B. D.; SOUZA, A. C.; SCHMITZ, V.; SILVA, A. C.; HIGUCHI, P. Análise quali-quantitativa da arborização urbana em Lages, SC. Revista de Ciências Agroveterinárias, Lages, v. 12, n. 1, p. 59-67, 2013.

SCHALLENBERGER, L. S.; ARAUJO, A. J.; ARAUJO, M. N.; DEINER, J.; MACHADO, G. O. Avaliação da condição de árvores urbanas nos principais parques e praças do município de Irati-PR. Revista da Sociedade Brasileira de Arborização Urbana, Piracicaba, v. 5, n. 2, p. 105-123, 2010. 
SILVA, L. M.; HASSE, I.; MOCCELIN, R.; ZBORALSKI, A. R. Arborização de vias públicas e a utilização de espécies exóticas: o caso do Bairro Centro de Pato Branco/PR. Scientia Agraria, Curitiba, v. 8, n. 1, p. 47-53, 2007.

SILVA, L. M. Reflexões sobre a identidade arbórea das cidades. Revista da Sociedade Brasileira de Arborização Urbana, Piracicaba, v. 3, n. 3, p. 65-71, 2008.

SILVA, L. M.; RODIGHIERO, D. A.; HASSE, I.; CADORIN, D. A. Arborização dos bairros Pinheiros, Brasília e Bancários em Pato Branco/PR. Scientia Agraria, Curitiba, v. 9, n. 3, p. 275-282, 2008.

SILVA FILHO, D. F.; BORTOLETO, S. Uso de indicadores de diversidade na definição de plano de manejo da arborização viária de Águas de São Pedro, SP. Revista Árvore, Viçosa, v. 29 , n. 6 , p. 973-982, 2005.

SOARES, M. P. Verdes urbanos e rurais: orientações para arborização de cidades e sítios campesinos. Porto Alegre: Cinco Continentes, 1998.

TOSCAN, M. A. G.; RICKLI, H. C.; BARTINICK, D.; SANTOS, D. S.; ROSSA, D. Inventário e análise da arborização do Bairro Vila Yolanda, do município de Foz do Iguaçu-PR. Revista da Sociedade Brasileira de Arborização Urbana, Piracicaba, v. 5, n. 3, p. 165-184, 2010.

VOLPE-FILIK, A.; SILVA, L. F.; LIMA, A. M. L. P. Avaliação da arborização de ruas do Bairro São Dimas na cidade de Piracicaba/SP através de parâmetros qualitativos. Revista da Sociedade Brasileira de Arborização Urbana, Piracicaba, v. 2, n. 1, p. 34-43, 2007. 